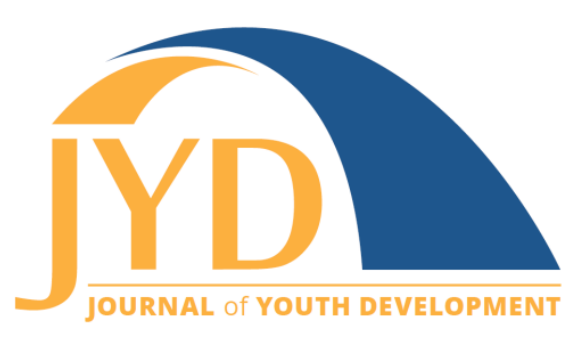

http://jyd.pitt.edu/ | Vol. 15 Issue 3 DOI 10.5195/jyd.2020.946 | ISSN 2325-4017 (online)

\title{
Fulfilling the Promise of Adolescence: Applying Developmental Knowledge to Create Systems Change
}

\author{
Dara Shefska \\ National Academies of Sciences, Engineering, and Medicine \\ dshefska@nas.edu \\ Emily P. Backes \\ National Academies of Sciences, Engineering, and Medicine \\ ebackes@nas.edu
}

\begin{abstract}
Adolescence-beginning with the onset of puberty and ending in the mid-20s-is a distinct developmental period marking the transition between early childhood and adulthood. Although adolescence is now understood as a period of exceptional learning and growth, it is still frequently characterized as a time of increased risk and vulnerability. This mischaracterization of adolescence, combined with the deeply rooted societal inequities, has left the promise of adolescence unrealized for too many youth. A recent report from the National Academies of Sciences, Engineering, and Medicine entitled The Promise of Adolescence: Realizing Opportunity for All Youth explores the socio-behavioral and neurobiological science of adolescence and provides recommendations for how this science can be applied by youthserving systems. This paper outlines the principles of adolescent development identified in the report and details 5 practices that can be implemented by youth-serving practitioners to promote positive adolescent development and ameliorate disparities in adolescent outcomes.
\end{abstract}

Key words: adolescence, education, health, child welfare, justice

Adolescence-beginning with the onset of puberty and ending in the mid-20s-is a distinct developmental period marking the transition between early childhood and adulthood.

Adolescence is characterized by pubertal maturation, strengthened capacity for learning, and the formation of personal identity.

(cc) EY New articles in this journal are licensed under a Creative Commons Attribution 4.0 License. This journal is published by the University Library System, University of Pittsburgh and is cosponsored by the University of Pittsburgh Press. The Journal of Youth Development is the official peer-reviewed publication of the National Association of Extension 4-H Agents and the National AfterSchool Association. 
While often thought of as a period of great risk and vulnerability, adolescence is more accurately portrayed as a period of great opportunity. As a 2019 National Academies of Sciences, Engineering, and Medicine report, The Promise of Adolescence: Realizing Opportunity for All Youth, ${ }^{1}$ finds, changes in brain structure and function during this period allow adolescents to explore their environments, build new relationships, discover, learn, and grow.

A key theme of the report is that the adolescent brain is malleable and plastic (for more information, see Chapter 2 of The Promise of Adolescence). While these attributes may sometimes be worrisome, the changes in brain structure and connectivity that happen during adolescence present young people with unique opportunities for positive, life-shaping development, and for recovery from past adversity.

A second important theme of the report is that the promise of adolescence is now unrealized for many adolescents in the United States due to deeply rooted structural inequalities that underpin well-documented disparities in developmental outcomes (see Chapter 4 of the report for more detailed discussion). These structural inequalities include substantial differences in family resources, the safety and support of neighborhoods, and the occurrence of racial/ethnic bias and discrimination. At a time in their lives when adolescents are becoming increasingly responsive to the environments around them, these inequities "get under the skin," affecting the brain and body in such a way that can shift trajectories for the worse.

The developmental science of adolescence, coupled with an equity perspective, challenges us to reimagine adolescence: shifting our frame from one preoccupied with risk and vulnerability to one that recognizes the opportunity of this developmental period and society's corresponding obligation to support our young people so that all adolescents have the chance to flourish and thrive. Investments in programs and interventions that capitalize on the brain's capacity to change during adolescence can promote beneficial shifts in young people's life trajectories, both

\footnotetext{
1 This article draws heavily from the recent report The Promise of Adolescence: Realizing Opportunity for All Youth released in 2019 and used with permission from the National Academies Press. Suggested citation for the full report: National Academies of Sciences, Engineering, and Medicine. 2019. The Promise of Adolescence: Realizing Opportunity for All Youth. Washington, DC: The National Academies Press. https://doi.org/10.17226/25388. The report was authored by the Committee on The Neurobiological and Sociobehavioral Science of Adolescent Development and Its Applications. Appreciation goes to Richard Bonnie, Joanna Lee Williams, and Natacha Blain for their reviews of earlier drafts of this article and to the committee for authoring the full report. The study was funded by the Funders for Adolescent Science Translation (The Annie E. Casey Foundation, the Bezos Family Foundation, the Chan Zuckerberg Initiative, the Conrad N. Hilton Foundation, the Ford Foundation, the Raikes Foundation, the Robert Wood Johnson Foundation, and the National Public Education Support Fund).
} 


\section{Fulfilling the Promise of Adolescence}

for youth who may have faced adverse experiences earlier in life, and for those who are facing challenges now.

This article focuses on five ways that individuals who work with youth, regardless of sector, can apply the principles of adolescent development to their work: helping young people and their families navigate social systems, enhancing equity within systems, providing culturally competent services, acknowledging and supporting adolescent agency, and increasing access to critical services, such as behavioral health services. These applications are discussed in detail below.

\section{Principles of Adolescent Development}

Part I of the report synthesizes the available neurobiological and socio-behavioral science of adolescence and puts forth six principles for policy and practice that emerge from that science (for a more detailed discussion of these principles, see pages 157-158 of the report). These six principles highlight features of adolescence particularly relevant for youth-serving systems and practitioners.

1. Adolescence is a sensitive period for discovery and learning, providing opportunities for life-long impact. The adolescent brain has evolved to meet the needs of this critical stage of life. A series of sensitive periods of brain maturation proceed from conception through adulthood. In adolescence, these developmental changes heighten curiosity and reward sensitivity and thereby invite exploration, discovery, and an associated tendency to take risks. By exploring new environments and developing new social relationships with peers and adults outside the family, adolescents build cognitive, social, and emotional skills necessary for mature relationships and productive contributions in adulthood.

2. Learning how to make decisions and to take responsibility for shaping one's own life are key developmental tasks of adolescence. Adolescents are active participants in their own development. Their developing competencies in problem-solving, their awareness of and concern with others, and their openness to exploration and novelty make this a particularly opportune time to support agency and leadership and promote engagement. While parents and other responsible adults must respect the developing agency of adolescents, they must also provide guidance to guard against impulsive or illconsidered decisions. 


\section{Fulfilling the Promise of Adolescence}

3. Forming personal identity is a key task of adolescence. The increasing diversity of U.S. adolescents and the nation as a whole requires youth-serving systems to be culturally sensitive and to be attuned to the integrated needs of each adolescent. Young people become increasingly aware of and attuned to their social status during adolescence, and institutions, policies, and practices may reinforce status hierarchies and stereotypes about members of groups that are nondominant or stigmatized in society. Moreover, adolescents have distinct physiological, socio-emotional, and cognitive needs that must be recognized and addressed as they mature.

4. Supportive familial, caregiver, and adult relationships play a significant role in fostering positive outcomes for adolescents. Adult caregivers are no less important for adolescents than they are for young children. Adolescents need secure attachment from adults as a foundation for healthy development and strong relationships.

5. Adolescence provides an opportunity for recovery and repair. Because of the malleability and plasticity of the adolescent brain, maladaptation in brain structure and behavior arising from stressful and harmful exposures during earlier developmental periods may be remediated during adolescence. Redirection, recovery, and resilience are possible. Insofar as the brain is healthy, individuals have the capacity for resilience.

6. Disparities in family and neighborhood resources and supports, biased and discriminatory interactions with important social systems, and resulting inequalities in opportunity and access severely curtail the promise of adolescence for many youth. Potent structural inequalities and other societal determinants shape adolescents' life trajectories, reducing access to the opportunities, services, and supports as well as exposing youth to risks, stresses, and demands that "get under the skin," adversely affecting the body and brain during this critical developmental period. These striking differences in opportunity are associated with differences in outcomes-in health, safety, well-being, and educational and occupational attainment-and in trajectories over the life course.

\section{Help Young People and Their Families Navigate Complex Systems}

As adolescents mature, they engage more and more with the social world, and they interact with social systems and organizations, including schools, law enforcement, businesses, and social services and health systems. For today's adolescents, the path to adulthood requires navigating a complex web of specialized social systems. This is especially true for young people who are involved in the child welfare or justice systems, which involve their own complicated 


\section{Fulfilling the Promise of Adolescence}

rules, processes, and procedures. Adolescents, and their parents and caregivers, need help navigating these increasingly complex social systems.

Take, for example, the process of applying to college. A successful college application might require an adolescent to navigate government systems (e.g., a FAFSA application as well as state financial aid forms), private company systems (e.g., the SAT, administered by the College Board), the education system (e.g., college applications, facilitating school-college communication), and the private consumer education market (e.g., private SAT tutoring). This ecosystem of specialized institutions poses distinct challenges for young people, particularly for socioeconomically disadvantaged youth.

This pattern repeats across systems and sectors. The health, education, justice, and child welfare sectors are all complicated systems that can be difficult to navigate without assistance or technical expertise. To address this challenge, systems, institutions, and practitioners should work to assist young people as they navigate these complex processes.

For example, in the area of health care, adolescents and their families need access to comprehensive, integrated, and coordinated services that allow them to seamlessly address all of their needs. Young people tend to view their health needs as interrelated (Brown et al., 2007; Gray et al., 2005; Manganello, 2008) and are new to navigating the health care system on their own, which can make it challenging for them to know where to turn when they need health services. Integrated, coordinated, and comprehensive services remove this barrier for adolescents, making it possible for them to receive the care they need to stay healthy during this important developmental period. For adolescents with special health care needs, coordinated, comprehensive, and integrated services are particularly important as they navigate multiple care providers and systems. State and federal health agencies, health systems, and health care providers should collaborate to provide integrated care for adolescents, linking physical and mental health providers as well as other vital support services to the health sector. For example, health care providers can support adolescents' growing autonomy by progressively empowering adolescents to participate meaningfully in their health care, in line with their maturity level.

In education, schools should support adolescents by identifying opportunities and resources to meet their specific educational and career needs, whether that be assisting with the college admissions processes or finding vocational training opportunities. For example, schools can 


\section{Fulfilling the Promise of Adolescence}

serve as placement coordinators, connecting their students with educational and vocational opportunities and resources in their community to meet their educational needs.

Moreover, for many adolescents, parents and caregivers are important partners in navigating complex social systems. But in some circumstances, parental involvement in systems can exacerbate challenges. In education, for example, youth rely on their parents and caregivers to advocate for preferred programs and courses in high school, to choose their schools through school-choice assignment systems, and to help them connect with resources and programs outside of school. Parental engagement in the education of their adolescents has been correlated with academic outcomes in middle and high school and may be protective against declines in academic achievement and engagement as adolescents move through middle and high school (Hill \& Tyson, 2009; Ratelle et al., 2004). However, effective parental engagement looks different during middle and high school than in elementary school, and parents and caregivers need to adjust accordingly. For example, caregivers will have to account for adolescents' drive for autonomy and independence and recognize that their adolescent children may not be willing to share information with them. Schools may be able to account for this by providing more and more frequent information to parents and caregivers about how their children are doing in school, a practice that can improve academic outcomes (Rogers \& Feller, 2018). It is important to note that for some parents and caregivers, engagement in their child's school may be particularly challenging. Families from socioeconomically disadvantaged circumstances may be less able to advocate for their adolescents within the education system and (or) help them navigate the education sector.

Moreover, in many circumstances, parents and caregivers have very little guidance as they navigate a sector or system with their adolescent child. In education, families may struggle to figure things out with few resources, increasing the risk of making uninformed decisions with long-term impacts. This is especially true for parents who did not attend college or for those who are developing proficiency in English.

While parents and caregivers are widely recognized as important partners for justice-involved youth, they often lack the legal knowledge to effectively help their adolescents navigate the justice system, and resources to teach them how to help their adolescents navigate the system are lacking (Davies \& Davidson, 2001, Feierman et al., 2011). This lack of knowledge can contribute to the youth's prolonged or more serious involvement with the justice system. For example, when under duress parents may make uninformed, rushed decisions or defer to those 


\section{Fulfilling the Promise of Adolescence}

in positions of authority to determine the fate of their adolescent child. Parents and adolescents from historically marginalized racial and ethnic or low-socioeconomic groups are most likely to be effectively disenfranchised in this process. Justice system actors, including probation programs, should connect parents and caregivers with community and educational resources that can teach them how to help their child succeed and avoid future interactions with the justice system.

In addition, families are living in the same context of societal change and complicated institutions as their adolescents. Structural barriers can tax families, especially those most in need of support, making decision-making more complex and stressful. Making resources more accessible may increase the cognitive and emotional bandwidth parents need to support adolescents more effectively. For example, practitioners can minimize technical jargon, complicated enrollment processes, and extraneous restrictions and instead meet adolescents and their families "where they are."

\section{Enhance Equity Within Systems}

For too many youth, the promise of adolescence is cut short by social, economic, or structural disadvantage, and all too frequently, by racism, bias, and discrimination. These powerful societal forces can shape young peoples' trajectories as they move through adolescence. Youth who face disadvantage or discrimination (or both) have reduced access to the opportunities, services, and supports enjoyed by more privileged youth and also are exposed to more risk, stresses, and demands. The consequences of such inequities can be long-lasting. Growing up in poverty, for example, has negative implications for the maturation of important regions of the brain such as the hippocampus and amygdala, which contribute to learning, memory, mood, and stress reactions (Brody et al., 2017). Poverty can also have lasting effects. Brody and colleagues (2017) found that childhood poverty was associated with reduced volume of brain limbic regions in adulthood.

In addition to the negative consequences of structural and social disadvantage, adolescents from historically marginalized groups face racism, bias, and discrimination. This discrimination may manifest as explicit and implicit (or unconscious) biases that individuals hold against groups defined by race, ethnicity, gender, LGBTQ identity, ability status, and other categories. These biases can be expressed in both one-time interactions as well as in a series of less obvious but frequent events, referred to as micro-aggressions. 
Because adolescents are especially sensitive to the attitudes and behaviors of adult members of the community, on whom they rely for information and encouragement with respect to careseeking behavior, effort exerted in school, and so on, experiencing these biases can result in disparities in outcomes for the affected groups. For example, a meta-analysis conducted by Tenenbaum and Ruck (2007) found that teachers often have different expectations and standards for their students based on students' race, ethnicity, gender, and sexuality, which are reflected in evaluations of student achievement and behavior. When a teacher has lower expectations of an adolescent's achievement based on the adolescent's group identity, this can have a harmful influence on actual achievement (Jussim \& Harber, 2005).

Although inequity during adolescence can have long-lasting consequences, these inequities are not immutable. The inequities that affect adolescents-disparities in family and neighborhood resources, and biased or discriminatory interactions with important social systems-can respond to changes in underlying conditions. While efforts are needed at the level of systems and policies, youth-serving practitioners can take specific steps to mitigate inequities in adolescent development.

To help all adolescents succeed, youth-serving professionals should engage in regular training on implicit bias and cultural sensitivity, both generally and as they relate to the specific populations that they serve. In addition, youth-serving programs can look to hire diverse staff who reflect the diversity of the young adults they serve. For example, a study from the health sector shows that when age-specific outpatient behavioral health services are available, service use among young people goes up (Gilmer et al., 2012).

\section{Provide Culturally Competent Services}

Today's youth population in the United States is more culturally and ethnically diverse than ever before, and family structures (e.g., blended families, grandparents as caregivers) are more diverse as well (Pearce et al., 2018). The U.S. population of adolescents ages 10 to 25 is expected to become minority majority in 2020, that is, with more than half belonging to a category other than non-Latinx White alone (Colby \& Ortman, 2014).

Against that backdrop, adolescents are working to answer the questions, "Who am I?" and "How do I see myself?" These questions are central to identity development, which is one of 


\section{Fulfilling the Promise of Adolescence}

the key developmental tasks of adolescence. An adolescent's identity is an emerging reflection of their values, beliefs, and aspirations, and can be formed and reformed with time and experience. In a pluralistic and multicultural society like the United States, adolescents' answers to the question of "Who am I?" is shaped by membership in multiple social groups: race, ethnicity, nationality, sexuality, gender, religion, political affiliation, ability status, and more. Having a strong connection to some aspect of social identity-whether race, gender, religion, or others-appears to be important for psychological well-being in adolescence (Kiang et al., 2008), and forming an integrated sense of self and coherent identity is associated with wellbeing in adulthood (Kroger \& Marcia, 2011, Meca et al., 2015, Schwartz et al., 2015). The growing racial and ethnic, social, and economic diversity of the country, combined with the salience of identity and social status in adolescence, calls for an emphasis on culturally competent services for adolescents. Culturally competent services have a focus on understanding differences in background and identify and assist youth with issues related to identity and social competence.

Youth-serving programs and practitioners can take action to provide culturally competent services for adolescents. For example, youth-serving practitioners should implement curricula that are culturally inclusive and affirm the value of the diverse ethnic and cultural backgrounds represented among U.S. students, both in their content and in learning styles. In education, schools and school districts should create curricular opportunities for culturally relevant content and exposure to the perspectives of non-dominant groups. Such practices may be beneficial for all adolescents. For example, a study of students who took a course in Mexican American studies found that students who took the course had higher rates of high school graduation and higher passing rates on state standardized tests compared to students who did not take the course (Cabrera et al., 2014).

\section{Support Adolescent Agency}

Adolescents are agents in their own development. Relative to young children, they have advanced decision-making skills which they can use to form long-term goals and work towards them. Indeed, learning how to make decisions and take ownership of one's life is one of the hallmarks of adolescence. However, this does not mean that adults do not have a role to play in helping adolescents make choices. While parents and other responsible adults must respect the emerging autonomy and agency of adolescents, they must also provide guidance and support to make this growth possible. 
Risk-taking during adolescence is a prime example. Relative to younger children and adults, adolescents are more sensitive to rewards. As such, their decision-making ability may skew more toward seeking the positive benefits of a choice and less toward avoiding potential risks (Davidow et al., 2016). This tendency, which has typically been viewed as a vulnerability of young people, can actually be used to their advantage, by enhancing learning and driving curiosity (Davidow et al., 2016). With appropriate monitoring and cushioning from caregivers and the community, adolescents can learn from missteps and take advantage of developmental opportunities.

Moreover, adolescents are capable of exercising good decision-making skills, but certain conditions are more conducive to positive choices than others. Research shows that youth make good decisions when those decisions are not emotionally charged, when they have practiced making similar decisions, when the people they look up to make similar decisions, and when an immediate "reward" is not offset by a consequence well into the future (Steinberg, 2005).

Given the importance of respecting agency for adolescents, people who work with youth can support their development not by making decisions for them, but by creating conditions in which they are more likely to make good decisions. Adolescents need both respect for their emerging autonomy and guidance as they learn to navigate the world on their own. They also need opportunities to exercise their growing self-direction skills in safe and healthy ways. Youth-serving practitioners have an important role to play in providing these opportunities to young people, and supporting their learning and exploration. For example, because of the higher-level cognitive, social, and emotional capacities of adolescents, youth involved in the child welfare system can participate in and play a lead role in decision making about their education, residential and custodial situations, and treatment and health care needs. Case managers and courts should ensure that adolescents have the opportunity to fully participate in developing and implementing their service and transition plans and view adolescents as respected partners in decision making.

Indeed, although young people are developmentally primed to want to make choices on their own, youth themselves state they are frequently apprehensive about taking on adult responsibilities for the first time (see Appendix $B$ of The Promise of Adolescence for more). Adolescents pointed to their lack of knowledge and experience with adult responsibilities as a common source of stress. They noted a desire for clear, straightforward guidance on how to 


\section{Fulfilling the Promise of Adolescence}

complete important "real world" tasks, like managing their personal finances and making doctor's appointments. Opportunities to gain such practical knowledge are frequently unavailable in schools, and youth from disadvantaged backgrounds may have less exposure to such knowledge. Youth-serving practitioners have an important role to play in filling this gap.

\section{Increase Access to Critical Services}

Access to appropriate services is important for adolescents, both to ensure their wellbeing today, as they experience the bumps and stresses of adolescent life, and to support their wellbeing in the future. This includes providing access to critical services that adolescents need to thrive, such as behavioral health care services, trauma-informed services, and education and health services for youth involved in the justice and child welfare systems.

\section{Behavioral Health Services}

Behavioral health services, including mental health services, are a critical component of adolescent health care. Given their unique social, behavioral, and neurobiological characteristics, adolescents are susceptible to mental and behavioral health disorders and in need of tailored treatment approaches. Adolescents themselves recognize this need as a high priority (see Appendix B of the report).

Yet despite this documented need, adolescents remain an underserved population in behavioral health care. This is due, in part, to barriers in access to services. To help adolescents meet their behavioral health care needs, service providers should work to "meet adolescents where they are." This includes providing services in schools, including colleges and universities. However, the young people whom the committee engaged reported that even when behavioral health services were available in their schools, they still faced barriers to access, such as long waiting lists, limits on the amount of accessible school-based services, and stigma.

One model for increasing youth's access to health services, including behavioral health services, is school-based care delivery. One in three adolescents who receive treatment for a mental illness do so in a school setting (Merikangas et al., 2011), and the presence and size of schoolbased mental health services can significantly impact suicide risk and substance use in adolescents (Paschall and Bersamin, 2018). The model of a school-based health center-in which health care services, including behavioral health, are provided to students within their 


\section{Fulfilling the Promise of Adolescence}

school-can increase young people's access to necessary care, especially for youth who are underinsured and uninsured or living in rural areas (Mason-Jones et al., 2012).

Another possible solution, put forth by youth themselves, is providing multiple sources of mental and behavioral health supports in schools. Teachers, school health staff, and mentors, they noted, could all play a role in supporting adolescents as they cope with stress. In light of this, youth-serving practitioners should consider the ways in which they can support the adolescents in their care, giving appropriate consideration to their scope of practice. Youthserving practitioners could seek training in identifying and responding to behavioral health concerns, and work to end stigma around behavioral health issues within their programs.

\section{Trauma-Informed Services}

Research from across disciplines has highlighted the potential impact of trauma on all aspects of an adolescent's development and functioning. Due to disparities in neighborhood and family resources, some adolescents may experience more trauma than others. Recognizing this, it is essential that those who encounter adolescents routinely understand how trauma may be manifested in context. This growing understanding has led to the development of traumainformed services. To be trauma-informed means to know the history of past and current abuse in the life of the person one is serving, no matter what the service setting. The implications for youth-serving practitioners are clear. Because trauma's impact is manifested during adolescence in ways that cut across all aspects of their development and behavior, the major initial challenge in becoming trauma-informed is how to recognize and identify trauma victims across the many varied settings that serve young people and places they congregate. The second challenge is how to engage these young people in services that can help them.

Harris and Fallot (2001) have identified five requirements for services to be truly traumainformed:

- administrative commitment to change, including allocating resources to ensure this;

- universal screening;

- trauma-specific training and education;

- ensuring that hiring practices are designed to recruit expertise in trauma; and

- $\quad$ ensuring that policies and procedures are sensitive to the issues faced by trauma victims. 


\section{Fulfilling the Promise of Adolescence}

So, for example, in after-school programs, program staff need to be informed about how, in the after-school setting, adolescent victims are frequently misidentified as presenting with behavioral and conduct disorders. Being trauma-informed requires being informed about and responsive to trauma, and providing a safe and stable environment for both students and staff, acknowledging trauma and its triggers, and avoiding stigmatizing and punishing students. One of the goals is to prevent re-traumatization (McInerney and McKlindon, 2014).

Models for trauma-informed approaches have been implemented in some settings. In education, schools in some states have adopted trauma-informed approaches, such as the Sanctuary Model, which engage educational leaders and staff to develop a culture where educators model and students develop safety, emotional management, self-control, and conflict resolution skills (McInerney \& McKlindon, 2014). Other models include the Cognitive Behavioral Intervention for Trauma in Schools, an evidence-based intervention that can be delivered in group settings or individually and that includes psychoeducation for parents and training for teachers.

In systems that work with adolescent populations that are disproportionately affected by trauma - child welfare and juvenile justice-there is an emerging literature on the implementation of trauma-informed approaches. For example, Ford and Blaustein (2013) describe trauma-informed approaches developed for juvenile justice systems and present guidelines for one model: Trauma Affect Regulation: Guide for Education and Therapy (TARGET). TARGET is an educational and therapeutic intervention for adolescents and adults that can be implemented as individual or group therapy and focuses on trauma-related dysregulation, reframing symptoms as adaptive responses. For the youth development field, implementing trauma-informed approaches is an important means for reducing disparities in outcomes along lines of race, ethnicity, and socioeconomic status.

\section{Cross-Sector Services for System-Involved Youth}

Young people who are engaged in either the justice or child welfare system, or both, face unique challenges in navigating the health and education systems. Adolescents involved in these systems often face challenges related to educational disruptions, course credit transfer, and lack of appropriate school placement and services. In terms of physical health, youth involved in the child welfare system report higher rates of physical health challenges, such as asthma and vision and hearing problems. Youth involved in the justice system have significantly higher rates of physical health conditions such as tuberculosis, sexually transmitted infections 


\section{Fulfilling the Promise of Adolescence}

(STIs), as well as behavioral health challenges like alcohol use, illegal drug use, and suicidality (American Academy of Pediatrics, 2011). Moreover, youth involved in the justice and child welfare systems are also more likely to have experienced previous traumas (National Center for Mental Health and Juvenile Justice, 2007).

Given these challenges, there is an urgent need for greater collaboration between the justice, child welfare, health, and education systems to support positive trajectories for system-involved youth. In both the child welfare and justice systems, state and local child welfare, justice, education, and health care agencies need to work together to ensure that youth involved in the child welfare and (or) justice systems are provided with appropriate health care and educational opportunities. System-involved adolescents need to be screened and treated for health issues at every stage of the system, including the time during which youth are transitioning out of the system. In the child welfare system, state and local child welfare and education agencies should collaborate to minimize educational disruptions for child welfare system-involved youth. This includes insuring proper transfer of credits, appropriate school placement and services, and school transportation services when continuation in the original school is desired. In the context of the justice system, states need support from federal, state, and local educational agencies and their communities to improve services for detained youth. Key to these supports are efforts to foster facility environments that prioritize education and provide the conditions for learning, to recruit and retain qualified educators, and to provide rigorous and relevant curricula aligned with state academic and career and technical education standards (U.S. Department of Education, 2015).

\section{Conclusion}

Adolescence - the developmental period spanning from the onset of puberty to the mid-20spresents opportunities for youth to learn and grow.

However, for too many adolescents, the promise of adolescence remains unrealized due to deeply rooted structural inequalities that underpin well-documented disparities in developmental outcomes. These inequities can "get under the skin" of adolescents, negatively affecting their physical and neurological development, and putting them on less positive pathways.

A central message of a 2019 National Academies of Sciences, Engineering, and Medicine report, The Promise of Adolescence: Realizing Opportunity for All Youth, is that more should be done 


\section{Fulfilling the Promise of Adolescence}

by actors at all levels to capture the promise of this developmental period. The report encourages society to reimagine adolescence as a period of opportunity and growth, rather than risk and vulnerability.

As trusted adults in adolescents' lives, youth-serving practitioners have an important role to play in helping adolescents take full advantage of this opportunity. The report identifies five ways in which all youth-serving practitioners, regardless of sector, can help realize the promise of adolescence:

1. helping young people and their families navigate social systems,

2. enhance equity within systems,

3. providing culturally competent services,

4. acknowledging and supporting adolescent agency, and

5. increasing access to critical services, such as behavioral health services.

These practices, informed by the developmental science of adolescence, can be used by youthserving practitioners to help adolescents reach their potential and to ameliorate inequities that hinder opportunity for so many adolescents.

\section{References}

American Academy of Pediatrics. (2011). Policy statement: Health care for youth in the juvenile justice system. Pediatrics, 128(6). https://doi.org/10.1542/peds.2011-1757

Brody, G. H., Yu, T., Chen E., \& Miller, G. E. (2017.) Family-centered prevention ameliorates the association between adverse childhood experiences and prediabetes status in young Black adults. Preventive Medicine 100, 117-122. https://doi.org/10.1016/j.ypmed.2017.04.017

Brown, S. L., Teufel, J. A., \& Birch, D. A. (2007). Early adolescents perceptions of health and health literacy. Journal of School Health, 771), 7-15. https://doi.org/10.1111/j.1746-1561.2007.00156.x

Cabrera, N. L., Milem, J. F., Jaquette, O., \& Marx, R. W. (2014). Missing the (student achievement) forest for all the (political) trees: Empiricism and the Mexican American studies controversy in Tucson. American Educational Research Journal, 51(6), 1084-1118.

Colby, S. L., \& Ortman, J. M. (2014). Projections of the size and composition of the U.S. population: 2014-2060. In Current Population Reports, P25-1143. U.S. Census Bureau.

Davidow, J. Y., Foerde, K, Galván, A., \& Shohamy, D. (2016). An upside to reward sensitivity: The hippocampus supports enhanced reinforcement learning in adolescence. Neuron, 92(1), 93-99. https://doi.org/10.1016/j.neuron.2016.08.031 
Davies, H. J., \& Davidson, H. A. (2001). Parental Involvement Practices of Juvenile Courts. Report to the Office of Juvenile Justice and Delinquency Prevention. American Bar Association.

Feierman, J., Keller, E.C., Glickman, M., \& Stanton, R. (2011). Navigating the Juvenile Justice System in Pennsy/vania: A Guide for Parents and Guardians. Juvenile Law Center.

Ford, J. D., \& Blaustein, M. E. (2013). Systemic self-regulation: a framework for trauma-informed services in residential juvenile justice programs. Journal of Family Violence, 28, 665-677. https://doi.org/10.1007/s10896-013-9538-5

Gilmer, T. P., Ojeda, V. D., Fawley-King, K., Larson, B., \& Garcia, P. (2012). Change in mental health service use after offering youth-specific versus adult programs to transition-age youths. Psychiatric Services, 63(6), 592-596. https://doi.org/10.1176/appi.ps.201100226

Gray, N. J., Klein, J. D., Noyce, P. R., Sesselberg, T. S., \& Cantrill, J. A. (2005). Health informationseeking behaviour in adolescence: The place of the internet. Social Science and Medicine, 60(7), 1467-1478. https://doi.org/10.1016/j.socscimed.2004.08.010

Harris, M., \& Fallot, R. D. (2001). Envisioning a trauma-informed service system. New Directions for Mental Health Services, 2001(89), 3-23. https://doi.org/10.1002/yd.23320018903

Hill, N. E., \& Tyson, D. F. (2009). Parental involvement in middle school: A meta-analytic assessment of the strategies that promote achievement. Developmental Psychology, 45(3), 740-763. https://doi.org/10.1037/a0015362

Jussim, L., \& Harber, K. (2005). Teacher expectations and self-fulfilling prophecies: Knowns and unknowns, resolved and unresolved controversies. Personality and Social Psychology Review, 9(2), 131-155. https://doi.org/10.1207/s15327957pspr0902 3

Kiang, L., Yip, T., \& Fuligni, A. J. (2008). Multiple social identities and adjustment in young adults from ethnically diverse backgrounds. Journal of Research on Adolescence, 18(4), 643-670. https://doi.org/10.1111/j.1532-7795.2008.00575.x

Kroger, J., \& Marcia, J. E. (2011). The identity statuses: Origins, meanings, and interpretations. In S. J. Schwartz, K. Luyckx, and V. L. Vignoles (Eds.), Handbook of Identity Theory and Research (pp. 31-53). Springer.

Manganello, J. A. (2008). Health literacy and adolescents: A framework and agenda for future research. Health Education Research, 23(5), 840-847. https://doi.org/10.1093/her/cym069

Mason-Jones, A. J., Crisp, C., Momberg, M., Koech, J., De Koker, P., \& Mathews, C. (2012). A systematic review of the role of school-based healthcare in adolescent sexual, reproductive, and mental health. Systematic Reviews, 1(1), 49. https://doi.org/10.1186/2046-4053-1-49

McInerney, M., \& McKlindon, A. (2014). Unlocking the door to learning: Trauma-informed classrooms \& transformational schools. http://www.vtnea.org/uploads/files/Trauma-Informed-in-SchoolsClassrooms-FINAL-December2014-2.pdf 
Meca, A., Ritchie, R. A., Beyers, W., Schwartz, S. J., Picariello, S., Zamboanga, B. L., Hardy, S. A., Luyckx, K., Kim. S. Y., Whitbourne, S. K., Crocetti, E., Brown, E. J., \& Benitez, C. G. (2015). Identity centrality and psychosocial functioning: A person-centered approach. Emerging Adulthood, 3(5), 327-339. https://doi.org/10.1177/2167696815593183

Merikangas, K. R., He, J. P., Burstein, M., Swendsen, J., Avenevoli, S., Case, B., Georgiades, K., Heaton, L., Swanson, S., \& Olfson, M. (2011). Service utilization for lifetime mental disorders in U.S. Adolescents: Results of the national comorbidity survey-adolescent supplement. Journal of the American Academy of Child and Adolescent Psychiatry, 50(1), 32-45. https://doi.org/10.1016/j.jaac.2010.10.006

National Academies of Sciences, Engineering, and Medicine. (2019). The promise of adolescence: Realizing opportunity for all youth. The National Academies Press.

\section{https://doi.org/10.17226/25388}

National Center for Mental Health and Juvenile Justice. (2007). Trauma among youth in the juvenile justice system: Critical issues and new directions. Author.

Paschall, M. J., \& Bersamin, M. (2018). School-based health centers, depression, and suicide risk among adolescents. American Journal of Preventive Medicine, 54(1), 44-50. https://doi.org/10.1016/j.amepre.2017.08.022

Pearce, L. D., Hayward, G. M., Chassin, L., \& Curran, P. J. (2018). The increasing diversity and complexity of family structures for adolescents. Journal of Research on Adolescence, 28(3), 591608. https://doi.org/10.1111/jora.12391

Ratelle, C. F., Guay, F., Larose, S., \& Senécal, C. (2004). Family correlates of trajectories of academic motivation during a school transition: A semiparametric group-based approach. Journal of Educational Psychology, 96(4), 743-754. https://doi.org/10.1037/0022-0663.96

Rogers, T., \& Feller, A. (2018). Reducing student absences at scale by targeting parents' misbeliefs. Nature Human Behaviour, 2(5), 335-342. https://doi.org/10.1038/s41562-018-0328-1

Schwartz, M. B., Henderson, K. E., Read, M., Danna, N., \& Ickovics, J. R. (2015). New school meal regulations increase fruit consumption and do not increase total plate waste. Child Obesity, 11(3), 242-247. https://doi.org/10.1089/chi.2015.0019

Steinberg, L. (2005). Cognitive and affective development in adolescence. Trends in Cognitive Sciences 9, 69. https://doi.org/10.1016/j.tics.2004.12.005

Tenenbaum, H. R., \& Ruck, M. D. (2007). Are teachers' expectations different for racial minority than for European American students? A meta-analysis. Journal of Educational Psychology, 99(2), 253273. https://doi.org/10.1037/0022-0663.99.2.253

U.S. Department of Education, Office for Civil Rights. (2015). Protecting civil rights, advancing equity: Report to the president and secretary of education, under section 203(b)(1) of the Department of 
Journal of Youth Development | http://jyd.pitt.edu/ | Vol. 15 Issue 3 DOI 10.5195/jyd.2020.946 Fulfilling the Promise of Adolescence

Education Organization Act, FY 13-14. https://www2.ed.gov/about/reports/annual/ocr/report-topresident-and-secretary-of-education-2013-14.pdf 